4. Lavonas EJ, Ruha A-M, Banner W, et al. Rocky Mountain Poison and Drug Center, Denver Health and Hospital Authority. Unified treatment algorithm for the management of crotaline snakebite in the United States: results of an evidence-informed consensus workshop. BMC Emerg Med. 2011;11:2.

5. Dayan L, Zinmann C, Stahl S, Norman D. Complications associated with prolonged tourniquet application on the battlefield. Mil Med. 2008;173:63-66.

\section{Backcountry Skiers, Avalanche Trauma Mortality, and Helmet Use}

\section{To the Editor:}

There is an increasing body of literature and awareness of trauma-associated mortality incurred by avalanche victims. ${ }^{1-3}$ A significant proportion of trauma-related mortality is attributed to head and cervical injuries. The intuitive response has been to emphasize protective strategies, including helmets.

However, recent studies suggest that the benefits of helmet use in resort skiers and snowboarders are mixed. Many report benefits, whereas others suggest the evidence is far from clear. Studies on the benefits of helmet use in backcountry skiers and snowboarders are lacking, and extrapolation from studies of similar user groups is the best information we have at this time.

Climbers and mountaineers who are exposed to rock and icefall are not included in this discussion. Climbing helmets are only standardized for falling objects on the crown, not side, front, rotational, and rear impacts. Human-powered backcountry skiers and snowboarders are the group I am discussing. It is the fastest growing segment of the ski and snowboard industry.

Several recent studies call into question the effectiveness of helmets preventing severe traumatic brain injury (TBI) among snow-sports users. Baschera et $\mathrm{al}^{4}$ recently found no decrease in severe TBI among alpine skiers, despite major increases in helmet use. They do mention off-piste users being at increased risk of severe TBI, but they also refer to these participants as "free riders," which is a different activity than the usual "earn your turns" participant.

Similarly, Christensen et $\mathrm{al}^{5}$ found an increasing rate of head injury in skiers and snowboarders despite a doubling of helmet use. This is in the context of ski resort participant numbers being flat for a decade or more. An increasing rate of head injury could certainly be attributed to many factors (increased awareness, diagnostic threshold, high rates of speed with modern equipment), but the finding is concerning and worrisome nonetheless. Importantly, children 10 and younger were found to have a decreasing incidence of head injury. However, young children are not typically backcountry users venturing into avalanche terrain.

Shealy et $\mathrm{al}^{6}{ }^{6}$ in 2008 , contended that helmet use in skiers and snowboarders prevented minor injuries, but serious TBI incidence and fatality rate were unaffected by helmet use. However, in 2014, Shealy et al ${ }^{7,8}$ added that helmet use was now having a positive impact in decreasing the potential incidence of serious TBI, yet still had no effect on fatality rate. Mountain fatalities seem to involve high-speed accidents, and it appears that the pattern of death may shift (from head to cervical spine and trunk injuries), but the outcome is likely to be the same. ${ }^{6,8}$

Analysis of injury mechanisms brings into question the use of helmets for lowering mortality from avalanche trauma. Modern snow-sport helmet technology is made to protect users from impacts at speeds of between 11 and $14 \mathrm{miles} / \mathrm{h}(18-23 \mathrm{~km} / \mathrm{h})$. Avalanches (along with their victims) travel at speeds of 60 to 80 miles/h (97$129 \mathrm{~km} / \mathrm{h}$ ), and take about 5 seconds to reach that speed. Forces of this magnitude outmatch our current helmet standards and likely affect the mortality rate of avalanche victims.

Another issue arises when backcountry enthusiasts take their helmets off to climb, or "skin," uphill. The rate at which backcountry skiers and snowboarders are caught in avalanches while ascending vs descending is unclear, with opinions ranging widely from $10 \%$ to $50 \%$ among avalanche experts (informal poll of avalanche forecasters and experts; anecdotal, not studied). The common practice of lashing a helmet to your backpack while ascending and being caught in a slide affords no benefit to the user. Helmets should be worn at all times (including skinning) to have a measurable impact.

A logical question then might be, is there any harm in helmet use? On the surface, this seems to be heretical. But if one digs past the assumptions, shortcomings begin to emerge. If protective equipment takes precedence over education, decision making, and other preventive behavior strategies, then there can be potential harm. Arming oneself with the latest beacon, probe, airbag, Avalung, and helmet are no substitute for practicing safe travel skills, terrain selection, snowpack evaluation, and rescue protocols. I am concerned that our culture that "treats every disease with a pill" all too often chooses gadgets over behavior modification and education. Outfitting oneself with all of the latest technology can bolster risk taking and confidence. ${ }^{9}$ The phrase "energy-drink culture" permeates a large portion of the targeted demographic, and has been used to describe prevailing attitudes toward risk.

It goes without saying that helmets will protect against lacerations, contusions, possibly fractures, and moderate 
speed (less than 15 miles/h) head injuries. Protection against concussions is debatable. The likelihood of lowering mortality in avalanche trauma when traveling at 60 to 80 miles/h wearing a current-technology helmet is highly unlikely. It is my hope that in the future we may see helmet technology improve to the point where they can prevent serious TBI, and be worn at all times, including while ascending.

In the meantime, to decrease avalanche fatalities from trauma, we should be emphasizing prevention strategies with avalanche education and skills practice. Safety helmet recommendations should be second or third tier, and the inherent limitations of helmet technology need acknowledgment. The lack of consistent evidence for preventing serious TBI among skiers and snowboarders and decreasing the fatality rate will hopefully spur improved helmet safety standards and effectiveness, science on the issue, and, subsequently, lives saved.

George Vargyas, MD

Intermountain Medical Center, Salt Lake City, Utah

\section{References}

1. Boyd J, Haeglei P, Abu-Laban RB, Shuster M, Butt JC. Patterns of death among avalanche fatalities: a 21-year review. CMAJ. 2009;180:507-512.

2. McIntosh SE, Grisson CK, Olivares CR, Kim HS, Tremper B. Cause of death in avalanche fatalities. Wilderness Environ Med. 2007;18:293-297.

3. Johnson SM, Johnson AC, Barton RG. Avalanche trauma and closed head injury: adding insult to injury. Wilderness Environ Med. 2001;12:244-247.

4. Baschera D, Hasler RM, Taugwalder D, Exadaktylos A, Raabe A. Association between head injury and helmet use in alpine skiers: cohort study from Swiss level 1 trauma center. J Neurotrauma. 2015;32:557-562.

5. Christensen ML, Jackson C. Skiing and snowboardingrelated head injuries in the United States: a retrospective analysis from 2004-2010. Wilderness Environ Med. 2013;24:81.

6. Shealy JE, Johnson RJ, Ettlinger CF. Do helmets reduce fatalities or merely alter the patterns of death? J ASTM Int. 2008:5.

7. Shealy JE, Johnson RJ, Ettlinger CF, Scher IS. Role of helmets in mitigation of head injuries: epidemiologic study of head injuries to skiers. In: Johnson RJ, Shealy JE, Greenwald RM, eds. Skiing Trauma and Safety: 20th Volume. STP1582 West Conshohocken, PA: ASTM International; 2015:22-38.

8. Researchers debate effectiveness of snow helmets. NPR broadcast, February 26, 2014. Available at: http://www.npr. org/2014/02/26/282836515/researchers-debate-effectivenes s-of-snow-helmets. Accessed October 2, 2015.

9. Ružić L, Tudor A. Risk-taking behavior in skiing among helmet wearers and nonwearers. Wilderness Environ Med. 2011;22:291-296.

\section{Ski Helmets and the Backcountry}

To the Editor:

I read with great interest the letter from Dr Vargyas ${ }^{1}$ concerning the use of ski helmets in the backcountry. I agree wholeheartedly that prevention is the cornerstone in reducing the incidence of ski and snowboarding injuries in the backcountry as well as during resortbased skiing. However, I must strongly disagree with his suggestion that the use of a ski helmet be labeled a "second- or third-tier recommendation." The debate over the effectiveness of ski helmets has already confused the public and industry alike to the point that even ski professionals have erroneous information concerning the use of helmets and a low adoption rate. ${ }^{2}$

Simply put, ski helmets have obvious limitations, but well-conducted research in the peer-reviewed medical literature has demonstrated that they are an effective tool for the prevention of traumatic brain injury in snow sports. ${ }^{3}$ There are no downsides to the use of ski helmets. Although I share some of Dr Vargyas's concerns over "gadgets" in lieu of appropriate behavior, the use of ski helmets does not increase the likelihood of riskier behavior (risk compensation). Scott et $\mathrm{al}^{4}$ phrased this more eloquently than I am able to:

Until published studies reveal that snow sport helmets produce risk compensation, there is little reason to presume helmets cause guests to ski or snowboard beyond their abilities and place themselves and others at greater risk of injury. This should provide comfort to industry leaders and injury prevention advocates alike. They should not be reluctant to recommend ski helmets based on fears of risk compensation.

Although I am hopeful that competition in the helmet industry will improve the current quality of helmets, it is unlikely that we will ever be able to produce a ski helmet that protects against high-velocity impacts. Consequently, it is the responsibility of the skier to ski under control at all times. However, it is interesting to note that research published in this journal found that even ski professionals ski at relatively slow speeds $(<15 \mathrm{mph})$ in the gladed areas that backcountry skiers are likely to encounter. $^{5}$

Those of us who are passionate about the backcountry enjoy the beauty and isolation of skiing in remote 